\title{
Interpretación jurisprudencial del beneficio de la semana corrida: violación del principio de igualdad de remuneraciones (Corte Suprema)
}

\section{Comentario de Pablo Arellano Ortiz e Ivonne Ponce Heinsobn}

Santiago, veintisiete de enero de dos mil once.

Dando cumplimiento a lo dispuesto en el artículo $483 \mathrm{C}$ inciso segundo del Código del Trabajo, se dicta la sentencia de reemplazo que sigue, en unificación de jurisprudencia.

\section{VISTOS:}

Se reproducen los fundamentos primero, segundo, tercero y quinto de la sentencia de nulidad de nueve de julio de dos mil diez, dictada por la Corte de Apelaciones de Valdivia, los que no se modifican con la decisión que se emite a continuación.

Y se tiene, además, presente:

PRIMERO: Que para la resolución del recurso de nulidad interpuesto por la parte demandada -y sólo en lo que interesa al recurso de unificación de jurisprudencia- preciso es consignar que se hizo valer la causal prevista por el artículo 477 del Código del Trabajo denunciando haberse expedido el fallo de primer grado con infracción al artículo 45 del Código del Trabajo, toda vez que se reconoció a favor de la demandante el derecho a semana corrida, disponiendo el pago de los cobros formulados en relación con este rubro en el libelo, sobre la base de sostener que el artículo recién mencionado, en su texto actual, sólo exige para estos efectos que el trabajador esté afecto a remuneración mixta, esto es, fija y variable, estableciéndose dos formas de cálculo según se trate de trabajadores remunerados exclusivamente por día, o en base a remuneración mixta como ya se indicó. Se añadió que el propósito del legislador, con la modificación introducida, fue incorporar al beneficio a los comisionistas u otros trabajadores que perciben remuneraciones variables, pero que no se condice con la historia del establecimiento de la ley discriminar entre trabajadores que perciben remuneraciones variables que se devengan día a día, y aquellos respecto de los cuales las mismas se devengan en plazos superiores - por ejemplo, mensualmente, cuyo es el caso de la trabajadora de autos-.

SEGUNDO: Que la controversia de derecho planteada en esta causa hace necesario dilucidar si la extensión del beneficio de semana corrida incorporado en el texto del inciso primero artículo 45 del Código del Trabajo por la Ley $\mathrm{N}^{\circ} 20.281$-alcanzando a quienes 
estén afectos al sistema mixto de remuneración integrado ahora por un sueldo mensual como componente fijo y además con un componente variable, en la especie, pago de comisiones-, supone o no como requisito habilitante que tales remuneraciones variables se devenguen por día, o, si por el contrario, se puede acceder al mismo al margen de la unidad de tiempo en que tales estipendios se incorporan al patrimonio del trabajador.

TERCERO: Que el inciso primero del artículo 45 del Código del Trabajo citado en el texto modificado dispone a la letra: "El trabajador remunerado exclusivamente por día tendrá derecho a la remuneración en dinero por los días domingo y festivos, la que equivaldrá al promedio de lo devengado en el respectivo período de pago, el que se determinará dividiendo la suma total de las remuneraciones diarias devengadas por el número de días en que legalmente debió laborar en la semana. Igual derecho tendrá el trabajador remunerado por sueldo mensual y remuneraciones variables, tales como comisiones o tratos, pero, en este caso, el promedio se calculará sólo en relación a la parte variable de sus remuneraciones.

CUARTO: Que cabe en primer lugar considerar que, al margen de la finalidad inmediata tenida en vista para instituir el pago de la semana corrida ligada a incentivar la asistencia al trabajo y cumplimiento de la jornada pactada, lo cierto es que responde de modo relevante al derecho a descaso remunerado, por los días domingos y festivos, para aquellos trabajadores cuya estructura o régimen de contraprestación por sus servicios, les impide devengar remuneración por esos días. De esta forma, el derecho en comento surge como una forma justa y necesaria para retribuir al trabajador remunerado por día, siendo este último elemento supuesto básico de la figura compensatoria por lo que se deja de percibir. En el curso de las diversas modificaciones legales concretadas en relación a este beneficio, desde su incorporación a través de la Ley N $\mathrm{N}^{\circ} 8.961$ de 1948 preciso es destacar aquélla introducida por la Ley $\mathrm{N}^{\circ} 18.018$, de 14 de agosto de 1981 , que especifica que accede a este derecho el trabajador remunerado "exclusivamente por día, sea que su remuneración sea fija por día, o variable y/o de forma mixta, con ambos componentes devengados diariamente, evento en el que el cálculo se haría en base al sueldo base diario. Luego, la Ley $\mathrm{N}^{\circ} 19.250$, de 30 de septiembre de 1993, que rigió hasta la modificación de la Ley $\mathrm{N}^{\circ}$ 20.281, mantuvo el beneficio para el trabajador remunerado exclusivamente por día, el que conforme a su tenor debía calcularse de acuerdo al promedio de la totalidad de las remuneraciones diarias, del período semanal, fueran estas fijas o variables, o mixtas, esto es, con ambos componentes de estipendios.

QUINTO: Que en las circunstancias antes descritas, al indicar la Ley $\mathrm{N}^{\circ} 20.281$ como nuevo contenido del inciso $1^{\circ}$ del artículo 45 del Código del Trabajo que "Igual derecho tendrá el trabajador remunerado por sueldo mensual y remuneraciones variables no está incorporando como elemento nuevo el derecho a semana corrida para quienes estén afectos a un sistema mixto de remuneraciones, fija y variable, toda vez que esa estructura remuneracional ya estaba considerada con anterioridad, y se mantenía en la primera parte del inciso primero, en el término "remunerado, que incluye tanto el 
componente fijo como variable, a condición de ser ambos devengados exclusivamente por día. Lo nuevo que incorpora al texto la Ley $\mathrm{N}^{\circ} 20.281$, es la posibilidad de generarse el beneficio no obstante que el componente fijo de tal remuneración mixta, sea mensual. Este elemento excepcional en el esquema de la semana corrida, que significó la flexibilización del componente fijo de la remuneración mixta, incorporando el sueldo mensual debió consagrarse así expresamente. Sin embargo, se añadió de inmediato que el cálculo del beneficio se llevaría a cabo "sólo en relación a la parte variable de sus remuneraciones toda vez que este componente es el que mantiene el espíritu y fisonomía de la semana corrida y, a su respecto no se innova, ni se estima necesario precisar una determinada unidad de tiempo para su devengamiento, porque es de la esencia de la institución que el estipendio sea devengado día a día. Siendo este último, el único elemento de la remuneración que se mantiene inalterable, -en cuanto se incorpora por cada día al patrimonio del trabajador- es evidente que el cálculo total del beneficio debe hacerse sólo en base al promedio que se obtenga a su respecto. En relación a este punto, y en armonía con la naturaleza y esencia de la semana corrida la Dirección del Trabajo, a través del Dictamen 3262/066, de 5 de agosto de 2008 -entre otros expedidos en el mismo sentido- expresó que si bien la modificación que la Ley No 20.281 de 21 de julio de 2008 introdujo al artículo 45 del Código del Trabajo significó extender el beneficio de semana corrida a los trabajadores con la remuneración mixta que allí se menciona, no pretendió en caso alguno modificar o aumentar la base de cálculo de este beneficio. Se especificó además que las remuneraciones variables que procede considerar para determinar la base de cálculo de la semana corrida deberán reunir los requisitos de: ser devengadas diariamente y además tener el carácter de principal y ordinaria.

Sobre este particular, resulta clarificador consignar, a propósito del proceso de formación de la norma, que el referido Proyecto de Ley del que resultó la modificación en análisis, nació por iniciativa del ejecutivo con la finalidad medular de adecuar el sueldo base mensual de los trabajadores que percibían remuneración mixta, al ingreso mínimo mensual, mediando una jornada ordinaria de trabajo, lo que se tradujo en la modificación del artículo 42 letra a) del Código del ramo. Estando el proyecto en el Senado, en segundo trámite constitucional, el Sr. Ministro del Trabajo y Previsión Social de la época advirtió que: "en ningún caso, se pretende generar por esta vía un mecanismo encubierto de mejoramiento de remuneraciones. "La mejoría en materia de remuneraciones, añadió, es un tema propio de las negociaciones entre empleadores y trabajadores, y en ese ámbito la iniciativa legal no incide. Así se aprecia del contenido del libro "Semana Corrida, de la autora Lucía Planet Sepúlveda, páginas 210 y 211.

SEXTO: Que extraer de la interpretación del nuevo texto del artículo 45 inciso $1^{\circ}$ del Código del Trabajo la conclusión de haberse extendido el beneficio de la semana corrida a un esquema remuneracional mixto en que ambos componentes, fijo y variable, pueden devengarse mensualmente -cuya es la situación fáctica que quedó fijada en estos autos-, significa desnaturalizar la institución que se analiza en tanto se pierde de vista la causa de compensar un día domingo o festivo no trabajado, si la remuneración, en su conjunto y en forma íntegra, se ha devengado por mes. 
En consecuencia, al haberse interpretado y decidido en la sentencia recurrida en un sentido diverso a lo que se razonó y concluyó en lo que precede, se ha infringido la norma del artículo 45 del Código del Trabajo, infracción que ha influido sustancialmente en lo dispositivo del fallo toda vez que condujo a acoger a favor de la parte actora prestaciones derivadas del beneficio de semana corrida, lo que resultaba del todo improcedente.

SÉPTIMO: Que en virtud de lo anteriormente consignado y habiéndose incurrido en el error de derecho denunciado en relación a la norma antes aludida, el recurso de nulidad sustantiva planteada sobre el particular por la parte demandada a fojas 31 y siguientes, deberá ser acogido. En consecuencia, debe entenderse unificada la jurisprudencia en el sentido anotado en los fundamentos que preceden, esto es, que los trabajadores incorporados en la parte final del inciso primero del artículo 45 del Código del Trabajo afectos a un sistema remuneracional mixto, integrado por sueldo mensual y remuneraciones variables, sólo tienen derecho al pago de la semana corrida, en la medida que sus remuneraciones variables sean devengadas día a día, y en cambio no lo tienen, si tales remuneraciones se devengan en una unidad de tiempo distinta.

Por estos fundamentos y lo dispuesto por los artículos 474, 477, 479, 480, 481 y 482 del Código del Trabajo se acoge, sin costas, el recurso de nulidad deducido por la parte demandada a fojas 31 y siguientes contra la sentencia de ocho de mayo de dos mil diez, escrita a fojas 9 y siguientes de estos antecedentes, la que, en consecuencia se invalida y se sustituye por la que se dicta a continuación sin nueva vista y en forma separada, a objeto de la coherencia y entendimiento necesarios al efecto.

Acordada con el voto en contra del Ministro señor Jacob, quien estuvo por desestimar el recurso de nulidad, considerando que no se ha incurrido en infracción de ley que justifique la invalidación solicitada, por las razones ya vertidas en el voto disidente que precede.

Redacción de la Ministra señora Rosa Egnem Saldías y del voto disidente su autor.

Regístrese.

Pronunciada por la Cuarta Sala de la Corte Suprema integrada por los Ministros señor Patricio Valdés A., señoras Gabriela Pérez P., Rosa Egnem S., señor Roberto Jacob Ch., y el Abogado Integrante señor Rafael Gómez B. No firma el Abogado Integrante señor Gómez, no obstante haber concurrido a la vista y al acuerdo de la causa, por estar ausente. Santiago, 27 de enero de 2011.

Autoriza la Ministra de Fe de la Excma. Corte Suprema.

$\mathrm{N}^{\circ}$ 6.019-10.

Santiago, veintisiete de enero de dos mil once.

\section{VISTOS:}

Se mantienen los motivos primero al sexto, y octavo, así como el párrafo final del fundamento undécimo, el párrafo primero del mismo con excepción de las frases: "como asimismo los domingos y festivos comprendidos entre el 21 de julio de 2008 y el 30 de noviembre de 2009, y “y por concepto de semana corrida, de la sentencia de la instancia, no afectados por la invalidación que antecede. 
Y se tiene, además presente:

PRIMERO: Los motivos primero al sexto, en su párrafo primero, del fallo de nulidad que precede, los que deben entenderse transcritos para estos efectos, resultando innecesaria su reproducción.

SEGUNDO: Que, con arreglo a lo ya razonado, y, establecido que la demandante se desempeñó como agente de ventas de la Administradora de Fondos de Pensiones demandada, sujeta a un sistema mixto de remuneraciones integrado por un sueldo mensual y otro componente variable consistente principalmente, en comisiones sobre las ventas que se devengaba también mensualmente, no cabe sino concluir que no le asiste el derecho al pago de semana corrida. En efecto, las comisiones o remuneraciones variables de los agentes de venta de Administradoras de Fondos de Pensiones no se devengan en forma diaria sino que luego de una serie de procesos y actos sucesivos en el tiempo que sólo permiten la incorporación de la comisión respectiva al patrimonio del trabajador cuando se concreta el primer pago de cotizaciones del nuevo afiliado o traspasado.

Por estos fundamentos y lo dispuesto además por los artículos 35, 42, 45, 456, 458y 459 del Código del Trabajo, se declara, que se rechaza la demanda deducida por doña Ana María Gómez Vega en contra de Administradora de Fondos de Pensiones Capital S.A., representada por doña Paola Tello Olivares, sólo en cuanto por ella se persigue que se condene a esta última a pagar a la actora lo correspondiente a remuneraciones por concepto de semana corrida y las diferencias que, en base a este estipendio, deben incrementar las otras prestaciones especificadas en el libelo, peticiones éstas que, en consecuencia, quedan desestimadas.

Se acoge, en lo demás pedido, y en lo no afectado por la invalidación precedente, la demanda antes referida.

Cada parte soportará sus costas.

Se deja constancia que el Ministro señor Jacob estuvo por mantener íntegramente las decisiones contenidas en la sentencia de la instancia en la forma que en ella se consignan, desde que en su concepto, resultaba improcedente acoger el recurso de nulidad como se dejó dicho en la resolución anulatoria.

Redacción de la Ministra señora Rosa Egnem Saldías y del voto disidente su autor.

Regístrese y devuélvase, con sus agregados.

Pronunciada por la Cuarta Sala de la Corte Suprema integrada por los Ministros señor Patricio Valdés A., señoras Gabriela Pérez P., Rosa Egnem S., señor Roberto Jacob Ch., y el Abogado Integrante señor Rafael Gómez B. No firma el Abogado Integrante señor Gómez, no obstante haber concurrido a la vista y al acuerdo de la causa, por estar ausente. Santiago, 27 de enero de 2011.

Autoriza la Ministra de Fe de la Excma. Corte Suprema.

$\mathrm{N}^{\circ}$ 6.019-10. 


\section{COMENTARio}

La sentencia de la Excelentísima Corte Suprema antes expuesta se dicta con la finalidad de unificar los criterios jurisprudenciales ${ }^{1}$ en torno a la extensión que se debe otorgar al beneficio de la semana corrida. Lo anterior resulta de suma importancia considerando las reformas introducidas a esta materia con la dictación de la Ley $\mathrm{N}^{\circ} 20.281^{2}$.

En ese escenario, la Corte Suprema decide que, para que el trabajador pueda impetrar dicho beneficio, es necesario que se encuentre sujeto a un régimen según el cual su remuneración sea devengada día a día, incluso en el evento de que estemos ante un trabajador sujeto a un sistema de remuneración mixta según consta en la reforma de la Ley $\mathrm{N}^{\circ} 20.281$.

Ahora bien, una cuestión previa que nos debemos representar antes de comentar el fallo es qué se debe entender por el beneficio de la semana corrida. Éste tiene por objeto otorgar al trabajador el derecho al pago de los días de descanso, en el evento de que su sistema de remuneración le impida devengar remuneraciones por aquellos días. Originariamente fue establecido por la Ley $\mathrm{N}^{\circ} 8.961^{3}$, cuyo objetivo fue establecer un beneficio que compensara la falta de ingresos del trabajador retribuido por día, el cual por ejercer su derecho al descanso no percibía pago alguno del empleador pagándosele en definitiva el día de descanso como si efectivamente hubiese sido trabajado. Hoy en día este beneficio es regulado por el artículo 45 del Código del Trabajo, siendo modificado posteriormente por la Ley $\mathrm{N}^{\circ} 20.281$ ya mencionada, que amplió el espectro de aplicación de la norma a los trabajadores remunerados por sueldo mensual y por remuneraciones variables ${ }^{4}$.

En este sentido, es preciso señalar que bajo la vigencia del antiguo artículo 45 del Código del Trabajo, este beneficio solo era aplicable a aquellos trabajadores remunerados exclusivamente por día. No obstante, con la mencionada modificación se incorporó a todo otro trabajador que percibiere además remuneraciones variables, lo que en definitiva determinó que existieran diversas interpretaciones respecto a la materia. Así, por ejemplo, antes de la sentencia de unificación dictada por la Corte Suprema existían fallos que hacían extensible el beneficio de la semana corrida tanto a los trabajadores que recibían remuneraciones variables que se devengaban día a día como a aquellos con remuneraciones devengadas mensualmente ${ }^{5}$.

\footnotetext{
${ }^{1}$ Artículo 483 Código del Trabajo.
}

${ }^{2}$ D .O. 21 de julio de 2008. Además ver la interpretación de esta ley efectuada por el Departamento Jurídico de la Dirección del Trabajo en el ORD N³262/066 de fecha 5 de agosto de 2008.

${ }^{3}$ D.O. 31 de julio de 1948.

${ }^{4}$ Inciso 1 artículo 45 Código del Trabajo: El trabajador remunerado exclusivamente por día tendrá derecho a la remuneración en dinero por los días domingo y festivos, la que equivaldrá al promedio de lo devengado en el respectivo período de pago, el que se determinará dividiendo la suma total de las remuneraciones diarias devengadas por el número de días en que legalmente debió laborar en la semana. Igual derecho tendrá el trabajador remunerado por sueldo mensual y remuneraciones variables, tales como comisiones o tratos, pero, en este caso, el promedio se calculará sólo en relación a la parte variable de sus remuneraciones.

5 Dentro de este grupo de sentencias encontramos por ejemplo: Corte de Apelaciones de Santiago, 14/06/2011, 4623-2010 Isapre Vida Tres S.A. con Dirección del Trabajo y Corte de Apelaciones de Santiago, 
Ahora bien, a nuestro entender el sentido y alcance que postula la Excelentísima Corte Suprema, representa una violación del principio de igualdad de remuneraciones en el ordenamiento jurídico chileno. Este principio implica que a igual trabajo igual salario. Por lo tanto, todo trabajador que realice el mismo trabajo debe ser remunerado de la misma manera, y entonces así se debe comprender que el período de descanso sea remunerado en forma igualitaria ${ }^{6}$. Dicha vulneración muestra una contradicción que necesita ser aclarada en vista de la protección de los trabajadores. Esta interpretación limita el campo de aplicación de la reforma de la Ley $\mathrm{N}^{\circ} 20.281$, y deja sin sustento la intención del legislador de extender este beneficio a un número mayor de trabajadores.

De esta manera, debemos señalar que la frase introducida por la Ley $\mathrm{N}^{0} 20.281$ indica explícitamente "igual derecho", sin expresar diferencia alguna. Así, lo correcto sería interpretar dicha frase haciendo referencia al beneficio del pago de los días domingos y festivos, es decir, a una remuneración por semana corrida sin distinción. Podemos de esta manera entender la reforma como un avance en la búsqueda de la igualdad de remuneraciones, teniendo así todos los trabajadores un pago por los períodos de descanso. Es de esta manera que se debe entender la intención del legislador al introducir esta frase y no como lo hace la jurisprudencia limitando este beneficio a quienes tengan remuneraciones variables devengadas día a día tales como en la situación existente antes de la reforma. La interpretación jurisprudencial, como es el caso que se comenta, no ha logrado un efecto extensivo y se aleja de la intención del legislador.

En la historia de la ley no constan muchos antecedentes sobre el objetivo de la reforma, ya que esta frase fue incorporada en el segundo trámite constitucional sin señalar su intención. Sin embargo, es en el voto disidente del fallo en comento que encontramos una mención expresa por parte de la Consfecove, en torno a incorporar dentro de este beneficio a aquellos trabajadores sujetos a un régimen de remuneración mixta cuyo componente variable se devengará mensualmente ${ }^{7}$.

Asimismo, la consecuencia del criterio expresado en el fallo en comento es que se excluyen trabajadores beneficiados, pese a que el legislador (tal como aparece de manifiesto en la historia de la ley) no tuvo intención alguna de distinguir ambos supuestos. Por tanto, si el legislador no distingue no le correspondería hacerlo al Juez.

En razón de todo lo expuesto, se produce en definitiva una falta de efectividad de la reforma porque no se ha alcanzado el objetivo de extender el beneficio a nuevos trabajadores. La jurisprudencia distingue entre las formas de pago y los trabajadores para limitar la aplicación de ésta, igualando además una situación que no debería. Además, no se tiene en cuenta que esta reforma tiene por objeto entregar el beneficio a categorías distintas de trabajadores de las que anteriormente gozaban de él; trabajadores que poseen

19/07/2010, 228-2010, María Angélica Pereira con Administradora de Fondos de Pensiones AFP Provida S.A

${ }^{6}$ Sobre el principio igualdad ver J. Rivero, «Rapport sur les notions d'égalité et de discrimination en droit public français», in, t. XIV 1961-1962, Dalloz 1965, pp. 343-360. Sobre la aplicación de este principio a las remuneraciones en derecho comparado: A. Lyon-Caen, «A travailégal, salaire égal. Une règle en quête de sens», juin 2006, 18; A. Jeammaud, «Du principe d'égalité de traitement des salariés», 2004, p. 694.

${ }^{7}$ Considerando 5 to del voto disidente del presente fallo. 
una estructura de sus remuneraciones diferente. Esta nueva categoría de trabajadores, en teoría nuevos beneficiados, tienen derecho al igual que los beneficiados previamente a recibir una remuneración durante los períodos de descanso, pues para ellos existen los mismos fundamentos para acceder al beneficio, esto basándonos en el principio de igualdad y sobre todo en la igualdad de remuneraciones ${ }^{8}$.

${ }^{8} \mathrm{La}$ doctrina ha destacado "el criterio asumido por la jurisprudencia... de que situaciones iguales deben ser tratadas iguales", ver Nogueira Alcalá, H., "El derecho a la igualdad en la jurisprudencia constitucional”, en Ius et Praxis, Facultad de Ciencias Jurídicas y Sociales, Universidad de Talca, Año 2, Número 2, p. 238. 